\title{
Meropenem vs standard of care for treatment of late onset sepsis in children of less than 90 days of age: study protocol for a randomised controlled trial
}

Irja Lutsar ${ }^{1 *}$, Ursula MT Trafojer ${ }^{2}$, Paul T Heath ${ }^{3}$, Tuuli Metsvaht ${ }^{4}$, Joseph Standing ${ }^{5}$, Susanna Esposito ${ }^{6}$, Vincent Meiffredy de Cabre ${ }^{7}$, Clarissa Oeser ${ }^{3}$ and Jean-Pierre Aboulker ${ }^{7}$, for The NeoMero Consortium ${ }^{8}$

\begin{abstract}
Background: Late onset neonatal sepsis (LOS) with the mortality of 17 to $27 \%$ is still a serious disease. Meropenem is an antibiotic with wide antibacterial coverage. The advantage of it over standard of care could be its wider antibacterial coverage and thus the use of mono-instead of combination therapy.

Methods: NeoMero-1, an open label, randomised, comparator controlled, superiority trial aims to compare the efficacy of meropenem with a predefined standard of care (ampicillin + gentamicin or cefotaxime + gentamicin) in the treatment of LOS in neonates and infants aged less than 90 days admitted to a neonatal intensive care unit. A total of 550 subjects will be recruited following a 1:1 randomisation scheme. The trial includes patients with culture confirmed (at least one positive culture from normally sterile site except coagulase negative staphylococci in addition to one clinical or laboratory criterion) or clinical sepsis (at least two laboratory and two clinical criteria suggestive of LOS in subjects with postmenstrual age $<44$ weeks or fulfilment of criteria established by the International Pediatric Sepsis Consensus Conference in subjects with postmenstrual age $\geq 44$ weeks). Meropenem will be given at a dose of $20 \mathrm{mg} / \mathrm{kg}$ q12h or q8h depending on the gestational- and postnatal age. Comparator agents are administered as indicated in British National Formulary for Children. The primary endpoint measured at the test of cure visit (2 days after end of study therapy) is graded to success (all baseline symptoms and laboratory parameters are resolved or improved with no need to continue antibiotics and the baseline microorganisms are eradicated and no new microorganisms are identified and the patient has received allocated treatment for $11 \pm 3$ days with no modification) or a failure (all remaining cases). Secondary outcome measures include comparison of survival, relapse rates or new infections by Day 28, clinical response at Day 3 and end of therapy, duration of hospitalisation, population pharmacokinetic analysis of meropenem and effect of antibiotics on mucosal colonisation and development of antibacterial resistance.

The study will start recruitment in September 2011; the total duration is of 24 months.
\end{abstract}

Trial registration: EudraCT 2011-001515-31

Keywords: randomised controlled trial, neonate, premature neonate, FP7

\footnotetext{
* Correspondence: irja.lutsar@ut.ee

'Institute of Microbiology, University of Tartu, Ravila 19, Tartu, 50411, Estonia

Full list of author information is available at the end of the article
} 


\section{Background}

A recent review including eight studies conducted in European and Australian neonatal wards showed that 80 to $93 \%$ of prescriptions are for off-label or unlicensed products [1]. In its $7^{\text {th }}$ framework programme the European Union has funded several projects that specifically aim to evaluate pharmacokinetics (PK), efficacy and safety of off-patent medicines in children. One project funded in 2010 is NeoMero-1, an open label, randomised, controlled superiority trial that aims to compare the efficacy of meropenem with a predefined standard of care (SOC) for the treatment of late onset sepsis (LOS) in neonates and infants aged less than 90 days (inclusive) admitted to a neonatal intensive care unit (NICU). The safety of study regimens as well as LOScausing microorganisms and their antibiotic susceptibility patterns, bacterial eradication-, relapse- and superinfection rates, mucosal colonisation with antibiotic resistant microorganisms and fungi, genetic markers that may affect response to therapy and the PK characteristics of meropenem will be described as secondary outcome measures.

\section{Late onset sepsis}

LOS is commonly defined as sepsis occurring 48 to 72 hours after birth, and is a serious disease with a mortality rate of $17 \%$ to $27 \%$ depending on the studied population [2-5]. Although LOS is predominantly caused by coagulase negative staphylococci (CoNS) accounting for 36-66\% of cases [3,4,6-8], Gram-negative rods Klebsiella pneumoniae, Escherichia coli, Serratia spp and Enterobacter cloacae are responsible for about $26-36 \%$ of cases $[4,6,9]$. In recent years the incidence of Gram negative infections appears to be increasing in many NICUs worldwide [10-12]. In an UK based microbiology laboratory survey, after exclusion of CoNS, the majority of LOS isolates were susceptible to the commonly used combinations of empiric antibiotics flucloxacillin, gentamicin, ampicillin and/or cefotaxime, however, relatively high resistance rates of Enterobacteriaceae to cephalosporins were reported $[3,13]$.

\section{Use of meropenem in neonates}

Meropenem is a low protein-bound (2\%) broad-spectrum carbapenem with the bactericidal activity resulting from inhibition of bacterial peptidoglycan synthesis in the cell wall. It is active against Gram-positive and Gram-negative bacteria including anaerobes and extended spectrum betalactamase and AmpC chromosomal $\beta$-lactamase producing Enterobacteriaceae [14]. The pharmacodynamics (PD) of meropenem is determined by the fraction of time free drug exceeds MIC ( $f \% \mathrm{~T}>\mathrm{MIC})$ with the target value of about $70 \%$ suggested for immunosuppressed adults and potentially for neonates [15].
The PK of meropenem in neonates has been described in three studies [16-18] but firm dosing recommendations have not yet been made. By using Monte Carlo simulations (MCS) two studies $[16,18]$ concluded that for most microorganisms a dose of $10 \mathrm{mg} / \mathrm{kg}$ or $20 \mathrm{mg} / \mathrm{kg}$ given twice or three times a day, depending on the gestational (GA) and postnatal age (PNA), is sufficient since $>90 \%$ of treated neonates will achieve PK/PD target attainment. One possible short-coming of the simulation approach taken by Bradley et al [18] was that MIC values were randomly allocated to simulated patients, thereby assuming MICs were known a priori, and many of the allocated MIC values were likely well below the accepted breakpoints for sensitivity. When designing dosing regimens, MIC is not known in advance and it is therefore preferable to recommend doses that will cover all organisms up to the sensitivity breakpoint which is usually $2 \mathrm{mg} / \mathrm{L}$ for meropenem (http://www.eucast.org). This approach was taken by van den Anker et al. [16] and in fact both authors emphasized that higher doses and 4hour infusion may be needed for microorganisms with increased MIC values, more specifically for Pseudomonas aeruginosa $[16,18]$. However, this may not be feasible due to the instability of meropenem (Summary of Product Characteristics). Whilst it is recommended that meropenem should be given within 1 hour of reconstitution, a recent study has shown that at a concentration of $4 \%$ at room temperature $\left(\leq 25^{\circ} \mathrm{C}\right)$ the degradation will be less than $10 \%$ over 12 hours [19].

The advantage of meropenem over standard of care might be its wider antibacterial coverage and thus the use of mono- instead of combination therapy.

\section{Clinical trials in LOS}

Despite the fact that a number of clinical studies in neonatal sepsis have been conducted previously, several methodological issues and the changing patient population make their results out of date and not applicable to the present population affected by LOS. It is remarkable that all 13 randomised controlled trials (RCT) are relatively old, dating from 1973 to 1992 [20]. With the exception of two studies, $[21,22]$ data on EOS and LOS were combined and neonatal and paediatric patients were reported together $[23,24]$. The variable proportion of missing outcomes as well as the small sample sizes in the two trials which included only LOS patients makes drawing meaningful conclusions from these studies also difficult. Our proposed NeoMero1 study is therefore designed to address many of these gaps in the literature.

\section{Methods and Design Eligible patients}

The study will include patients with confirmed as well as clinical sepsis (Figure 1). Confirmed sepsis will be 


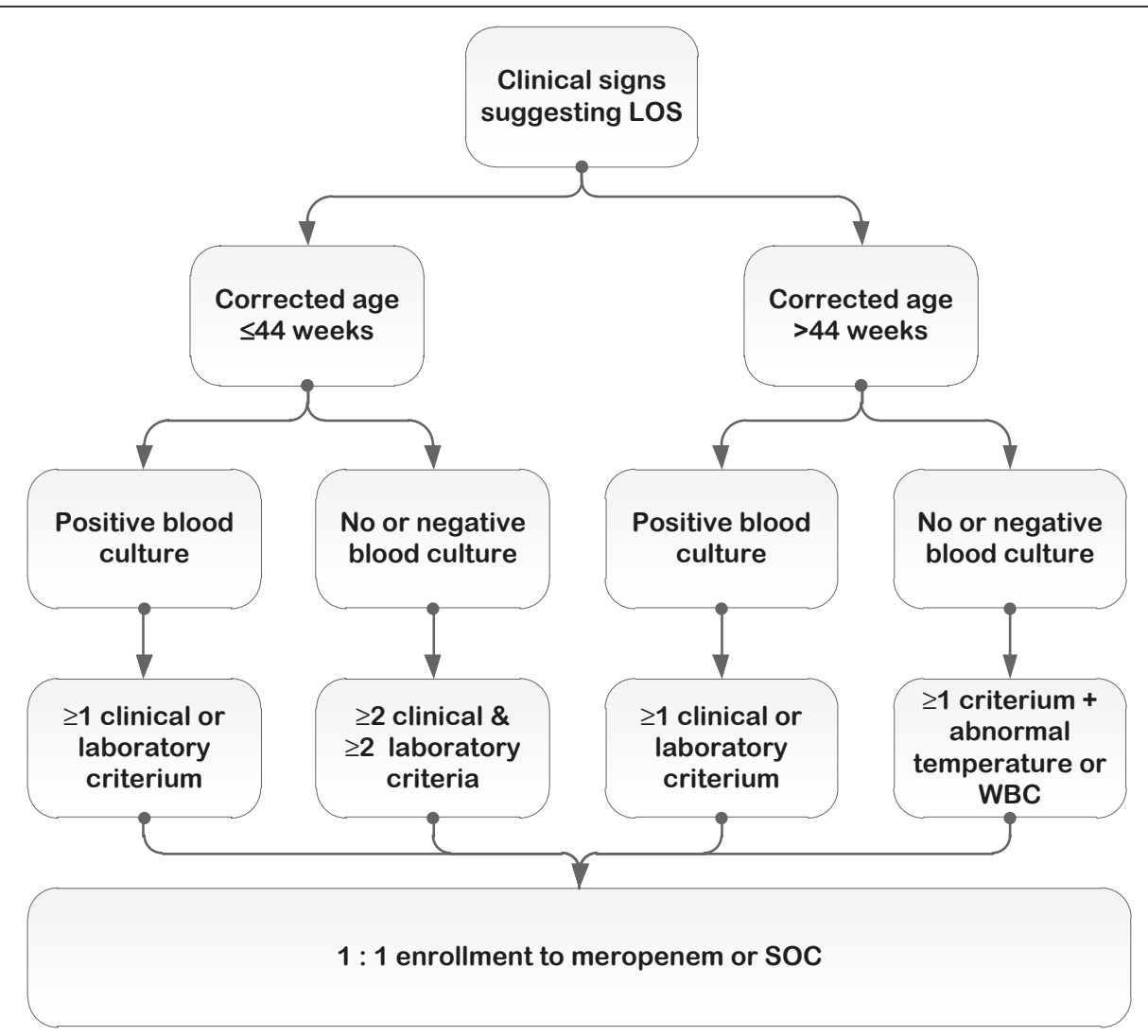

Figure 1 Flowchart of the NeoMero1 study.

defined as at least one positive bacterial culture (except CoNS) from a normally sterile site at baseline together with an abnormal clinical or laboratory parameter within the last 24 hours prior to randomisation (as listed below). Clinical sepsis in patients equal or older than 44 weeks of postmenstrual age is based on the criteria defined by the International Pediatric Sepsis Consensus Conference [25]. For patients below 44 weeks of postmenstrual age, the criteria of clinical sepsis were agreed at the Expert Meeting on Neonatal and Paediatric Sepsis on 8 June 2010, EMA London (http://www.ema.europa. eu/docs/en_GB/document_library/Report/2010/12/ WC500100199.pdf) and consist of a combination of at least two abnormal clinical and two abnormal laboratory parameters within the 24 hours prior to randomisation. The relevant clinical criteria are (1) hyper- or hypothermia or temperature instability; (2) reduced urinary output or hypotension or mottled skin or impaired peripheral perfusion; (3) apnea or increased oxygen or increased ventilatory support requirement; (4) bradycardia spells or tachycardia or rhythm instability; (5) feeding intolerance or abdominal distension; (6) lethargy or hypotonia or irritability; (7) skin and subcutaneous lesions such as petechial rash or sclerema. The relevant laboratory criteria are: (1) white blood cells count $(\mathrm{WBC})<4$ or $>20 \times 10^{9}$ cells $/ \mathrm{L}$; (2) immature to total neutrophil $(\mathrm{I} / \mathrm{T})$ ratio $>0.2$; (3) platelet count $<100 \times$ $10^{9} / \mathrm{L}$; (4) C-reactive protein (CRP) $>15 \mathrm{mg} / \mathrm{L}$ or procalcitonin $\geq 2 \mathrm{ng} / \mathrm{mL}$; (5) glucose intolerance when receiving normal glucose amounts $(8-15 \mathrm{~g} / \mathrm{kg} /$ day $)$ as expressed by blood glucose values $>180 \mathrm{mg} / \mathrm{dL}$ or hypoglycemia $(<40 \mathrm{mg} / \mathrm{dL})$ confirmed on at least two occasions; (6) acidosis with base excess $(\mathrm{BE})<-10$ $\mathrm{mmol} / \mathrm{L}$ or lactate above $2 \mathrm{mmol} / \mathrm{L}$.

Patients who have received systemic antibiotics for more than 24 hours (except when judged as treatment failure), have organisms suspected or known to be resistant to study therapies or are not expected to survive for more than 3 months due to congenital abnormalities, will be excluded as well as patients with renal failure or known intolerance or contraindications to the study medications.

\section{Study treatments}

Meropenem dose for this study was set at $20 \mathrm{mg} / \mathrm{kg}$ q $8 \mathrm{~h}$ (q12h for neonates with GA $<32$ weeks and PNA $<2$ weeks) based on the results of a previous PK study [18]. The main question to be addressed was infusion length, 
as giving the same dose but varying the infusion length will change $\mathrm{f} \% \mathrm{~T}>\mathrm{MIC}$ without affecting the area under the curve (AUC) and therefore overall exposure [16]. Using PK parameters and their uncertainty from an ongoing study in the USA [unpublished interim model kindly provided by Dr EV Capparelli], we performed simulations to investigate the effect of infusion length on $\mathrm{f} \% \mathrm{~T}>\mathrm{MIC}$ using the current EUCAST susceptibility cut-off for Enterobacteriaceae of $2 \mathrm{mg} / \mathrm{L}$ (http://www. eucast.org). These simulations showed that infusion times of $0.5,1$ and 2 hours gave $90 \%$ of patients with f\% $\mathrm{T}>\mathrm{MIC}$ of at least $44 \%, 48 \%$, and $50 \%$, respectively with a skewed distribution meaning that at least $60 \%$ in all age groups had $\mathrm{f} \% \mathrm{~T}>\mathrm{MIC}$ of $100 \%$ (Figure 2 ). Clearly increasing infusion length increased $\mathrm{f} \% \mathrm{~T}>\mathrm{MIC}$, but given concerns over meropenem's stability and that at least $44 \% \mathrm{f} \% \mathrm{~T}>\mathrm{MIC}$ was achieved for $90 \%$ of patients, a 30 minute infusion was finally recommended.

The two most commonly used antibiotic regimens for LOS (ampicillin + gentamicin or cefotaxime + gentamicin) were selected as SOC knowing that both regimens cover the vast majority of LOS causing agents and have been in use for several decades [13]. To minimise the potential bias of an open label design, each participating unit will select just one of these two regimens prior to start of the study and will then use it throughout the study. The dosages for the comparator agents were selected as recommended in the BNFC (edition of 20102011; http://www.bnfc.org).

The use of other systemic antibacterials will not be allowed with the exception of vancomycin and other suitable antibiotics for the treatment of infections proven or suspected to be caused by methicillin-resistant CoNS or Staphylococcus aureus. The use of topical antiinfectives, systemic antifungals, antivirals, immunglobulins and probiotics is allowed and will be recorded in the case report form.

\section{Ethical aspects}

Since the treatment of LOS is an emergency situation requiring immediate commencement of antibacterial treatment it will not always be possible to obtain the informed consent (IC) prior to the first dose of any antibiotic. Therefore the study will allow the enrolment of patients who have been given antibiotics for LOS according to the local guidelines for less than 24 hours. This avoids restricting the study to the less severe cases where treatment can be delayed until IC has been signed. For the study analysis patients will be stratified according to whether or not they received prior antibiotics.

The study aims to minimise interventions made purely for study purposes. First, all study antibiotics (including meropenem) are widely used for the treatment of LOS in the participating units despite the fact that none of them is labelled for neonates [26]. Second, few procedures will be conducted only for study purposes; PK samples, genetic samples and specific microbiologic tests will preferably be collected when routine clinical sampling is done; the collection of stool samples does not cause any extra distress to the baby/infant. Furthermore, the amount of blood collected for the PK-study $(0.3 \mathrm{ml}$ on a maximum of 3 times) has proven to be safe for ELBW babies [27].

The study has been approved by the Ethics Review Committee University of Tartu (205T-18).

\section{Monitoring of clinical and laboratory parameters}

In addition to routine clinical monitoring, patients will be assessed for specific clinical signs and symptoms and for laboratory abnormalities at baseline, on Day 3, at the end of the antibacterial- and study treatment and in patients with a successful outcome, two days after stopping study treatments (test of cure visit - TOC). At all time points, clinical symptoms and laboratory parameters will be graded and compared with those at baseline. They will be categorised as improved, stable or worsened according to prespecified criteria. For monitoring relapses, reinfections, new infections and late safety issues a Day 28 follow up visit will be conducted for all patients with a successful outcome at TOC visit. This follow-up (FU) visit is optional and may be replaced by a telephone interview if necessary in patients with treatment failure. An auditory assessment will also be undertaken at any time up until the FU assessments. Finally, a separate study will invite patients at the corrected age of 20 to 24 months to neurodevelopmental and auditory testing if the latter was abnormal in the acute period.

\section{Microbiological assessments}

Microbiological samples will be collected at baseline and on Day 3 and also whenever clinically indicated; they will be processed in local microbiology laboratories. Clinically significant isolates from blood or CSF will be stored at $-80^{\circ} \mathrm{C}$ and sent for identification and antibacterial susceptibility to a central microbiology laboratory in order to ensure uniformity.

To compare the effect of study antibiotics on colonisation by antibiotic resistant microorganisms and fungi, stool samples or perianal swabs will be collected on admission, at the end of study therapy and at hospital discharge or the follow up visit (whichever is earliest). For a combination of techniques such as the detection of 16 S ribosomal DNA [28], organism specific PCRs and microarray techniques $[29,30], 0.5 \mathrm{~mL}$ of whole blood will be taken on admission and again on Day 3. Molecular techniques will be used to improve the detection of pathogens where conventional bacterial cultures are negative. 


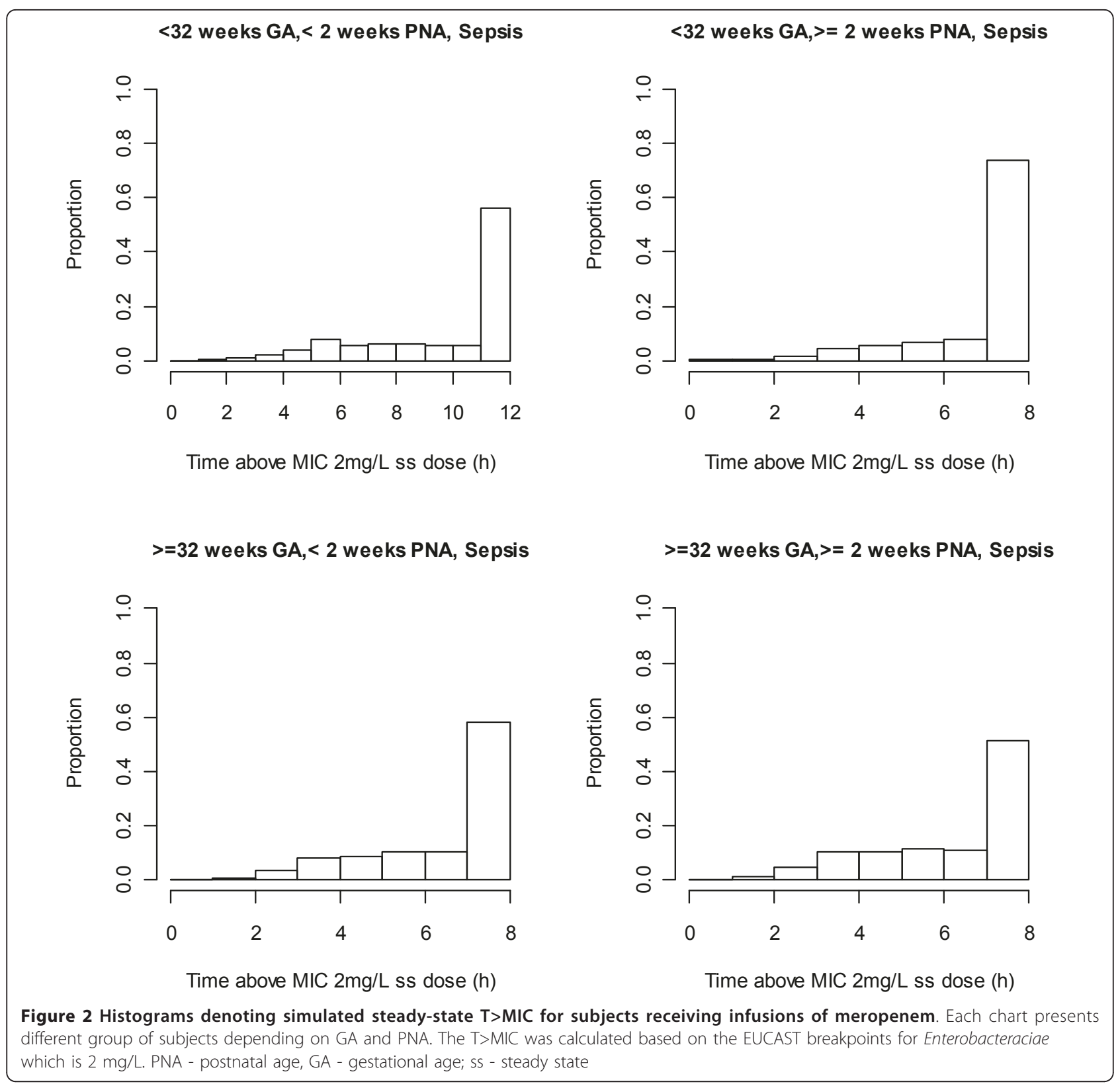

\section{Selection of optimal time points for PK sampling}

Using the previously mentioned interim PK model parameters and their uncertainty, we undertook an ED-Optimal design exercise to ascertain when to take samples given the following scenarios: a small cohort of full profile subjects with 3 post-dose samples, and the remaining subjects providing a single PK sample. Optimal sampling times were found to be $0.5,7-8$ and 12 hours post dose for those dosed 12 hourly and 0.5 , 5-6 and 8 hours post-dose for those dosed 8 hourly. For the single sample subjects, the optimal time was a trough sample.

\section{Statistical aspects}

We opted for an efficacy trial. The superiority of meropenem over SOC is mainly expected from its wider coverage of responsible pathogens and from its potential use as monotherapy. We estimate that, in the control arm, $15 \%$ of patients will die before the TOC visit and among those who survive the proportion of failing subjects will be $25 \%$ [4,31]. Thus, the proportion of neonates who will die or fail therapy in the comparator arm is expected to be $36.25 \%$. It is hypothesized that in the meropenem arm the survival will be improved to $90 \%$ and the failure rate will drop to $15 \%$ in surviving neonates. Thus, the 
expected proportion of neonates who will die or fail therapy should be reduced to $23.5 \%$. Based on these assumptions, the required sample size to provide $80 \%$ power to show the superiority of meropenem over SOC, using a continuity-corrected chi-square test with a two-sided 5\% alpha level, is 220 subjects per arm (NQuery software). We also anticipate that 15 to $20 \%$ of randomised neonates will ultimately have conditions not amenable to study antibiotics, although fulfilling the initial criteria of clinical sepsis, and thus decrease the apparent treatment size effect. Consequently, the sample was conservatively increased by $25 \%$, thus the total population of the study will be 275 neonates per study arm.

The primary endpoint is a combination of clinical and microbiological criteria measured at the TOC visit and defined to a success (the patients is alive, all baseline symptoms and laboratory parameters are resolved or improved so that there is no need to continue antibacterial treatment, the baseline microorganisms are eradicated, there are no new microorganisms identified and patient has received allocated treatment for $11 \pm 3$ days with no modification) and a failure (all remaining cases).

Primary efficacy analysis will compare success rates in the two arms in all randomised subjects in an intent to treat approach. Subsidiary analyses of the primary endpoint by the stratification factors (SOC regimen, timing of antibiotic therapy initiation) will also be performed in the full analysis set and the confirmed sepsis subset. Various secondary analyses including comparison of survival and relapse rates or new infections by Day 28, clinical response at Day 3 and end of therapy visits, clinical and bacteriological response and duration of hospital stay will also be evaluated.

\section{Discussion}

The evidence base for novel anti-infective treatments is limited in newborns, despite their high-risk status for infection and their vulnerability to its consequences. To our best knowledge, this is the first randomised controlled study in neonates and young infants with LOS conducted in the modern era of neonatal care. Although it is generally accepted that with antibiotics efficacy data in paediatric patients may not be needed as it might be extrapolated from adults, neonates are an exception [32]. It is possible that due to the immaturity of the immune system, the required PK/PD targets in critically ill neonates differ from those in adults, but we are not aware of these targets having been established [15].

A major challenge for all studies concerning LOS is the lack of validated clinical and laboratory criteria in situations where obtaining blood cultures is difficult, sample volumes are small, a substantial number of cultures could be negative or contaminated, and almost all clinical symptoms are non-specific. While the International
Pediatric Sepsis Consensus Conference criteria [25] could be used for infants and neonates of postmenstrual age of 44 weeks and above, validated criteria for premature babies, accounting for the majority of LOS cases, are almost completely lacking. Modi et al. [33] have developed a predictive model of 12 predefined clinical criteria for LOS and suggested that the presence of three or more clinical symptoms has the best predictive accuracy for positive blood culture in premature neonates. Adding increased CRP into the model reduced the accuracy; this is not surprising as CRP is a late rather than early marker of infection. Others have shown that laboratory markers such as a platelet count $<100,000 / \mathrm{ml}$ [34], procalcitonin concentration $>2.3-2.4 \mathrm{ng} / \mathrm{ml}[35,36]$ or CRP $>10 \mathrm{mg} / \mathrm{L}$ [37] are beyond normal ranges in premature babies. Evaluation of clinical symptoms is often subjective and could potentially introduce additional bias especially in a multicenter and international setting. So we have agreed on a combination of at least two clinical symptoms and at least two laboratory parameters to define clinical sepsis. We hypothesize that using these criteria the number of patients not having LOS will be minimised. Fairly similar criteria for LOS were used by one of the NeoMero Consortium partners in a previous study [38] and were also agreed by the EMA expert panel in June 2010 (http:// www.ema.europa.eu/docs/en_GB/document_library/ Report/2010/12/WC500100199.pdf).

To describe the PK/PD properties of meropenem, a population PK (popPK) analysis approach will be used as this allows a description of the variability in PK parameters and their dependence on patient characteristics. PopPK also allows the pooling of sparse data in many subjects in order to make predictions of $\mathrm{f} \% \mathrm{~T}>\mathrm{MIC}$ and its variability given a model derived from the data; the use of this technique for antimicrobial studies is increasingly recommended [39]. We have been able to inform the study design through simulation, in this case to define infusion length, and optimal PK sampling [40]. We have ensured that maximal information can be gained from the minimally invasive sampling schedule that has necessarily been imposed due to resource, logistical and patient characteristics in the proposed study. Whilst the recommended infusion time of 30 minutes does not achieve our original target of $\mathrm{f} \% \mathrm{~T}>\mathrm{MIC}$ of $70 \%$, it has been suggested that $\mathrm{f} \% \mathrm{~T}>\mathrm{MIC}$ of $40 \%$ is sufficient for the bactericidal activity of carbapenems in patients with a functioning immune system [39]. Furthermore, our simulations present a worst-case scenario, in that many of the microorganisms we expect to encounter will have MIC values significantly lower than the EUCAST breakpoints. Through the use of population PK/PD modelling and MCS, the model created from the extensive data collected in this study will determine the optimal dose and infusion duration of meropenem. 
An unresolved issue in neonatal studies, especially when dealing with patients in critical conditions or requiring rapid therapeutic interventions, is obtaining written IC. Several aspects were considered by the NeoMero Consortium. We appreciate that obtaining an IC prior to randomisation could be extremely challenging. It is expected that the vast majority of potential participants will be severely ill babies and the parents may not be available to sign the IC straight away. Although not proven in neonates, significant evidence from adult studies supports the role of immediate appropriate antibacterial treatment in reducing mortality in severe sepsis or septic shock [41]. Therefore in this study the following options to obtain IC will be explored in agreement with local regulations and Ethics Committees' position. First, written IC for potential LOS cases will be obtained around the time of the NICU admission. The downside of this option involves unnecessary consent in many patients and a possible change in the parent's opinion on participation with the sublimation of the status from a well-baby to a baby with a potentially life threatening illness. On the other hand, this procedure guarantees the parents a longer cooling-off period and offers more possibilities to seek further information before signing the consent form. The other option would be to consent over the phone and ask for signed consent when parents are next in the hospital. A pragmatic option is therefore to seek consent at the time of the study procedures where possible but also, in recognition that the study objectives will not be significantly affected, to obtain consent even after other antibiotic treatment has been commenced. None of these strategies is ideal and the preference will also depend on local requirements. This issue is not specific to the NeoMero studies and might be one of the reasons that no studies have been conducted in neonatal sepsis over the last 20 years despite the fact that most antibiotics in neonates are used off-label [26].

We appreciate that the ideal study design would be a blinded rather than an open label study. However, due to various antibiotic susceptibilities of pathogens in participating countries and differences in medical practices, finding a single acceptable comparator regimen appeared too complicated. Blinding would further be compromised by the fact that meropenem monotherapy is to be compared with a combination of comparator agents (ampicillin or cefotaxime plus gentamicin). A dummy infusion in critically ill, premature babies might lead to fluid overload and result in deterioration of the babies' condition. In an attempt to minimise potential bias the study sites have to commit to a specific comparator regimen prior to initiation of the study rather than at the time of randomisation, as this be influenced by their perception of the severity of the baby's illness.

Another controversial issue is the influence of meropenem or other broad spectrum antibiotics on the intestinal microflora. Some studies have suggested that broad spectrum antibiotics interfere with the development of intestinal microflora via outselection of antibiotic resistant microorganisms which may persist for several months $[42,43]$. Others, however, show that selection of resistant organisms is not associated with broad spectrum antibiotics but rather with the duration of the NICU stay and the presence of indwelling catheters $[44,45]$. This study provides an opportunity to assess the influence of different regimens on intestinal microflora in a controlled setting.

\section{Conclusions}

Patients are planned to be randomised from September 2011. The results of the study should provide useful data on efficacy, safety and PK/PD of meropenem in the treatment of LOS in neonates and infants up to 90 days of age. In addition, data about immunogenetics of LOS as well as the distribution of causative agents and their antimicrobial resistance patterns will be provided. By providing a comprehensive list of prospectively collected data the study will also fulfil an important gap in our knowledge of neonatal sepsis. The data could then be used for further dose modelling for other antibiotics and likely allow more appropriate extrapolations of efficacy data from adult studies.

\section{Acknowledgements}

The study is funded by the European Community's Seventh Framework Programme (FP7/2007-2013) under grant agreement $n^{\circ} 242146$. JFS is supported by a Methodology Fellowship G1002305 from the UK Medical Research Council. IL and TM are partly supported by the grants of Estonian Science Foundation (8799) and Estonian Target Financing (SF0182726s06) and from the European Union through the European Regional Development Fund and the Archimedes Foundation.

On behalf of the NeoMero Consortium: PENTA, Padova, Italy - Carlo Giaquinto, Children's Hospital Bambino Gesù, Rome, Italy - Paolo Rossi, University of Milan, Italy - Susanna Esposito, St George's, University of London, UK - Mike Sharland, INSERM Clinical Trial Unit, Paris, France - JeanPierre Aboulker, ESPID - Ulrich Heininger, University of Tartu, Estonia - Irja Lutsar, Aristotle University, Thessaloniki, Greece - Emmanuel Roilides, Radboud University Nijmegen Medical Centre, Netherlands - Adilia Warris, Vilnius University, Lithuania - Vytautas Usonis, University Hospital LA PAZ, Madrid, Spain - Félix Omeñaca Terés, Consorcio per le Valutazione Biologiche e Farmacologiche - Adriana Ceci

\section{Author details}

${ }^{1}$ Institute of Microbiology, University of Tartu, Ravila 19, Tartu, 50411, Estonia. ${ }^{2}$ Neonatal Intensive Care Unit, Department of Pediatrics, Via Giustiniani 3, Padova, 35128, Italy. ${ }^{3}$ Division of Clinical Sciences, St George's, University of London, Cranmer Terrace, Londo, SW17 ORE, UK. ${ }^{4}$ Clinic of Anaesthesiology and Intensive Care, University Clinics of Tartu, Lunini 6, Tartu, 50411, Estonia. ${ }^{5}$ Infectious Diseases and Microbiology Unit, Institute of Child Health University College London, 30 Guilford Street, London, WC1N 1EH, UK. ${ }^{6}$ Department of Maternal and Pediatric Sciences, Università degli Studi di Milano, Fondazione IRCCS Ca' Granda Ospedale Maggiore Policlinico, Via Commenda 9, Milano, 20122, Italy. ${ }^{7}$ INSERM SC10, 16, avenue Paul-Vaillant Couturier, Villejuif, 94807, France. ${ }^{8}$ Via Giustiniani 3, 35128, Padova, Italy.

\section{Authors' contributions}

$I \mathrm{~L}$ and UT are principle investigators of the study, participated in the design of the study and drafted the manuscript; TM and PTH, participated in the 
design of the study and drafted the manuscript; CO and SE participated in the design of the study; JFS designed the pharmacokinetic part of the study and drafted relevant parts in the manuscript; VMC and JPA participated in the design of the study and performed statistical analysis. All authors read and approved the final manuscript.

\section{Competing interests}

The authors declare that they have no competing interests.

Received: 18 July 2011 Accepted: 30 September 2011

Published: 30 September 2011

\section{References}

1. Lindell-Osuagwu L, Korhonen MJ, Saano S, Helin-Tanninen M, Naaranlahti T, Kokki H: Off-label and unlicensed drug prescribing in three paediatric wards in Finland and review of the international literature. J Clin Pharm Ther 2009, 34:277-287.

2. Mehr SS, Sadowsky JL, Doyle LW, Carr J: Sepsis in neonatal intensive care in the late 1990s. J Paediatr Child Health 2002, 38:246-251.

3. Vergnano S, Menson E, Kennea N, Embleton N, Russell AB, Watts T, Robinson MJ, Collinson A, Heath PT: Neonatal infections in England: the NeonIN surveillance network. Arch Dis Child Fetal Neonatal Ed 2010, 96 : F9-F14.

4. Stoll BJ, Hansen N, Fanaroff AA, Wright LL, Carlo WA, Ehrenkranz RA, Lemons JA, Donovan EF, Stark AR, Tyson JE, et al: Late-onset sepsis in very low birth weight neonates: the experience of the NICHD Neonatal Research Network. Pediatrics 2002, 110:285-291.

5. McGuire W, Clerihew L, Fowlie PW: Infection in the preterm infant. Bmj 2004, 329:1277-1280

6. Bizzarro MJ, Raskind C, Baltimore RS, Gallagher PG: Seventy-five years of neonatal sepsis at Yale: 1928-2003. Pediatrics 2005, 116:595-602.

7. Cohen-Wolkowiez M, Moran C, Benjamin DK, Cotten CM, Clark RH, Benjamin DK Jr, Smith PB: Early and late onset sepsis in late preterm infants. Pediatr Infect Dis J 2009, 28:1052-1056.

8. Hira V, Sluijter M, Estevao S, Horst-Kreft D, Ott A, de Groot R, Hermans PW, Kornelisse RF: Clinical and molecular epidemiologic characteristics of coagulase-negative staphylococcal bloodstream infections in intensive care neonates. Pediatr Infect Dis J 2007, 26:607-612.

9. Larson EL, Cimiotti JP, Haas J, Nesin M, Allen A, Della-Latta P, Saiman L: Gram-negative bacilli associated with catheter-associated and noncatheter-associated bloodstream infections and hand carriage by healthcare workers in neonatal intensive care units. Pediatr Crit Care Med 2005, 6:457-461.

10. Toltzis P: Colonization with antibiotic-resistant Gram-negative bacilli in the neonatal intensive care unit. Minerva Pediatr 2003, 55:385-393.

11. Nambiar S, Singh N: Change in epidemiology of health care-associated infections in a neonatal intensive care unit. Pediatr Infect Dis J 2002, 21:839-842.

12. Bizzarro MJ, Dembry LM, Baltimore RS, Gallagher PG: Changing patterns in neonatal Escherichia coli sepsis and ampicillin resistance in the era of intrapartum antibiotic prophylaxis. Pediatrics 2008, 121:689-696.

13. Muller-Pebody B, Johnson AP, Heath PT, Gilbert RE, Henderson KL, Sharland M: Empirical treatment of neonatal sepsis: are the current guidelines adequate? Arch Dis Child Fetal Neonatal Ed 2011, 96:F4-8.

14. Moon YS, Chung KC, Gill MA: Pharmacokinetics of meropenem in animals, healthy volunteers, and patients. Clin Infect Dis 1997, 24(Suppl 2):S249-255.

15. Lutsar I, Metsvaht T: Understanding pharmacokinetics/pharmacodynamics in managing neonatal sepsis. Curr Opin Infect Dis 2010, 23:201-207.

16. van den Anker JN, Pokorna P, Kinzig-Schippers M, Martinkova J, de Groot R, Drusano GL, Sorgel F: Meropenem pharmacokinetics in the newborn. Antimicrob Agents Chemother 2009, 53:3871-3879.

17. van Enk JG, Touw DJ, Lafeber HN: Pharmacokinetics of meropenem in preterm neonates. Ther Drug Monit 2001, 23:198-201.

18. Bradley JS, Sauberan JB, Ambrose PG, Bhavnani SM, Rasmussen MR, Capparelli EV: Meropenem pharmacokinetics, pharmacodynamics, and Monte Carlo simulation in the neonate. Pediatr Infect Dis J 2008, 27:794-799.

19. Berthoin K, Le Duff CS, Marchand-Brynaert J, Carryn S, Tulkens PM: Stability of meropenem and doripenem solutions for administration by continuous infusion. J Antimicrob Chemother 2010, 65:1073-1075.
20. Gordon A, Jeffery HE: Antibiotic regimens for suspected late onset sepsis in newborn infants. Cochrane Database Syst Rev 2005, CD004501.

21. Miall-Allen VM, Whitelaw AG, Darrell JH: Ticarcillin plus clavulanic acid (Timentin) compared with standard antibiotic regimes in the treatment of early and late neonatal infections. Br J Clin Pract 1988, 42:273-279.

22. Umana MA, Odio CM, Castro E, Salas JL, McCracken GH Jr: Evaluation of aztreonam and ampicillin vs. amikacin and ampicillin for treatment of neonatal bacterial infections. Pediatr Infect Dis J 1990, 9:175-180.

23. Begue $P$, Astruc J, Francois $P$, Floret D: Evaluation de la ceftraixone et du cefotaxime dans l'infection bacterienne severe en pediatrie: etude multicentrique. Med Mal Infect 1997, 27:300-306.

24. Haffejee IE: A therapeutic trial of cefotaxime versus penicillin-gentamicin for severe infections in children. J Antimicrob Chemother 1984, 14(Suppl B):147-152.

25. Goldstein B, Giroir B, Randolph A: International pediatric sepsis consensus conference: definitions for sepsis and organ dysfunction in pediatrics. Pediatr Crit Care Med 2005, 6:2-8.

26. Lass J, Kaar R, Jogi K, Varendi $H$, Metsvaht T, Lutsar I: Drug utilisation pattern and off-label use of medicines in Estonian neonatal units. Eur $J$ Clin Pharmacol 2011

27. Heidmets LT, Metsvaht T, IImoja ML, Pisarev H, Oselin K, Lutsar I: Blood loss related to participation in pharmacokinetic study in preterm neonates. Neonatology 2011, 100:111-115.

28. Chan KY, Lam HS, Cheung HM, Chan AK, Li K, Fok TF, Ng PC: Rapid identification and differentiation of Gram-negative and Gram-positive bacterial bloodstream infections by quantitative polymerase chain reaction in preterm infants. Crit Care Med 2009, 37:2441-2447.

29. Fujimori M, Hisata K, Nagata S, Matsunaga N, Komatsu M, Shoji H, Sato H, Yamashiro Y, Asahara T, Nomoto K, Shimizu T: Efficacy of bacterial ribosomal RNA-targeted reverse transcription-quantitative PCR for detecting neonatal sepsis: a case control study. BMC Pediatr 2010, 10:53.

30. Tissari P, Zumla A, Tarkka E, Mero S, Savolainen L, Vaara M, Aittakorpi A, Laakso S, Lindfors $M$, Piiparinen $\mathrm{H}$, et al: Accurate and rapid identification of bacterial species from positive blood cultures with a DNA-based microarray platform: an observational study. Lancet 2010, 375:224-230

31. Benjamin DK, DeLong E, Cotten CM, Garges HP, Steinbach WJ, Clark RH: Mortality following blood culture in premature infants: increased with Gram-negative bacteremia and candidemia, but not Gram-positive bacteremia. J Perinatol 2004, 24:175-180.

32. Lutsar I, Friedland I: Clinical Trials of Anti-Infective Agents in Paediatrics. In Basel, Karger. Edited by: Rose K, van den Anker JN. Guide to Paediatric Drug Development and Clinical Research; 2010:2170-2177.

33. Modi N, Dore CJ, Saraswatula A, Richards M, Bamford KB, Coello R, Holmes A: A case definition for national and international neonatal bloodstream infection surveillance. Arch Dis Child Fetal Neonatal Ed 2009, 94:F8-12.

34. Guida JD, Kunig AM, Leef KH, McKenzie SE, Paul DA: Platelet count and sepsis in very low birth weight neonates: is there an organism-specific response? Pediatrics 2003, 111:1411-1415.

35. Turner D, Hammerman C, Rudensky B, Schlesinger Y, Schimmel MS: The role of procalcitonin as a predictor of nosocomial sepsis in preterm infants. Acta Paediatr 2006, 95:1571-1576.

36. Auriti $C$, Fiscarelli $E$, Ronchetti MP, Argentieri M, Marrocco G, Quondamcarlo A, Seganti G, Bagnoli F, Buonocore G, Serra G, et al: Procalcitonin in detecting neonatal nosocomial sepsis. Arch Dis Child Fetal Neonatal Ed 2011

37. Chiesa C, Natale F, Pascone R, Osborn JF, Pacifico L, Bonci E, De Curtis M: C reactive protein and procalcitonin: reference intervals for preterm and term newborns during the early neonatal period. Clin Chim Acta 2011, 412:1053-1059.

38. Metsvaht T, IImoja ML, Parm U, Maipuu L, Merila M, Lutsar I: Comparison of ampicillin plus gentamicin vs. penicillin plus gentamicin in empiric treatment of neonates at risk of early onset sepsis. Acta Paediatr 2010 99:665-672.

39. Drusano GL: Antimicrobial pharmacodynamics: critical interactions of 'bug and drug'. Nat Rev Microbiol 2004, 2:289-300.

40. Dodds MG, Hooker AC, Vicini P: Robust population pharmacokinetic experiment design. J Pharmacokinet Pharmacodyn 2005, 32:33-64.

41. Paul M, Shani V, Muchtar E, Kariv G, Robenshtok E, Leibovici L: Systematic review and meta-analysis of the efficacy of appropriate empiric 
antibiotic therapy for sepsis. Antimicrob Agents Chemother 2010,

54:4851-4863

42. Linkin DR, Fishman NO, Patel JB, Merrill JD, Lautenbach E: Risk factors for extended-spectrum beta-lactamase-producing Enterobacteriaceae in a neonatal intensive care unit. Infect Control Hosp Epidemiol 2004, 25:781-783.

43. Almuneef MA, Baltimore RS, Farrel PA, Reagan-Cirincione P, Dembry LM: Molecular typing demonstrating transmission of gram-negative rods in a neonatal intensive care unit in the absence of a recognized epidemic. Clin Infect Dis 2001, 32:220-227.

44. Millar M, Philpott A, Wilks M, Whiley A, Warwick S, Hennessy E, Coen P, Kempley S, Stacey F, Costeloe K: Colonization and persistence of antibiotic-resistant Enterobacteriaceae strains in infants nursed in two neonatal intensive care units in East London, United Kingdom. J Clin Microbiol 2008, 46:560-567.

45. Parm U, Metsvaht T, Sepp E, Ilmoja ML, Pisarev H, Pauskar M, Lutsar I: Risk factors associated with gut and nasopharyngeal colonization by common Gram-negative species and yeasts in neonatal intensive care units patients. Early Hum Dev 2011, 87:391-399.

doi:10.1186/1745-6215-12-215

Cite this article as: Lutsar et al: Meropenem vs standard of care for treatment of late onset sepsis in children of less than 90 days of age: study protocol for a randomised controlled trial. Trials 2011 12:215.

\section{Submit your next manuscript to BioMed Central} and take full advantage of:

- Convenient online submission

- Thorough peer review

- No space constraints or color figure charges

- Immediate publication on acceptance

- Inclusion in PubMed, CAS, Scopus and Google Scholar

- Research which is freely available for redistribution

Submit your manuscript at www.biomedcentral.com/submit 